\title{
Integrated Research on Olfactory and Geomagnetic Imprinting and Homing in Pacific Salmon
}

\author{
Hiroshi Ueda ${ }^{1,2}$, Nathan F. Putman ${ }^{3}$, and Tatsufumi Okino ${ }^{4}$ \\ ${ }^{1}$ Hokkaido University, Sapporo, Hokkaido 063-0813, Japan \\ ${ }^{2}$ Hokkaido Aquaculture Promotion Corporation, Sapporo, Hokkaido 003-0874, Japan \\ ${ }^{3}$ Nathan F. Putman, LGL Ecological Research Associates, Bryan, Texas 77802, USA \\ ${ }^{4}$ Hokkaido University, Sapporo, Hokkaido 060-0810, Japan
}

Keywords: olfaction, geomagnetic map, imprinting, homing, natal river, navigation, migration

Pacific salmon are recognized for their amazing abilities to memorize their natal river information during a short-distance downstream migration, carry out a long-distance feeding migration in the ocean for many years for growth, and make a precise long-distance spawning migration from oceanic feeding habitat to their natal river for reproduction. Two different sensory mechanisms, olfaction, and magnetoreception, are involved in the imprinting and homing processes in Pacific salmon. It is believed that olfactory imprinting occurs from the spawning ground to the mouth of a natal river, and olfactory homing occurs from the vicinity of the river mouth to the spawning ground of a natal river (Ueda 2019, 2020); Geomagnetic imprinting is thought to occur as juveniles depart the mouth of their natal river to oceanic nursery habitat, and geomagnetic homing occurs from the oceanic feeding habitat back to the mouth of their natal river (Putman 2018, 2021) (Fig. 1). This report presents current findings on olfactory and geomagnetic imprinting and homing in Pacific salmon and proposes an international collaborative research project to test olfactory and geomagnetic imprinting and homing in Pacific salmon across the Pacific Ocean.

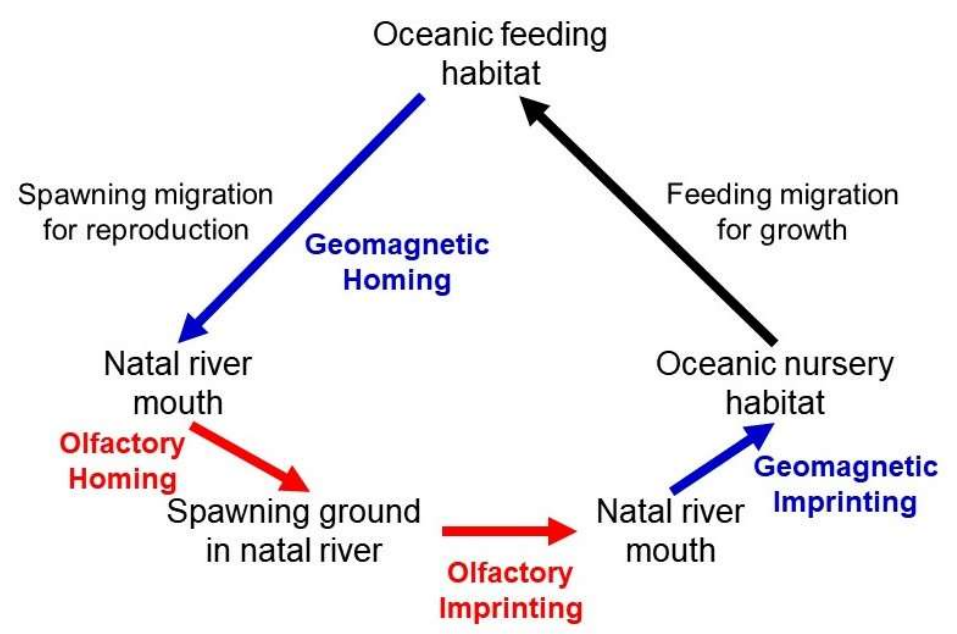

Fig. 1. Salmon migration loop showing olfactory and geomagnetic imprinting and homing.

Salmon olfactory organs respond to a relatively narrow suite of dissolved chemical compounds, such as amino acids, steroids, bile acids, and prostaglandins (Hara 1994). Electrophysiological responses of the olfactory nerve in masu salmon to artificial stream water (ASW) based on the composition of dissolved free amino acid (DFAA) closely resembled responses elicited by the corresponding natural stream water (Shoji et al. 2000). In the Teshio River in Hokkaido, Japan, juvenile chum salmon undergo their downstream migration in spring, and adults undergo their upstream migration in autumn; there is an average four-year span between the juvenile downstream and adult upstream migration. The Teshio River water contained 15 DFAAs, and the concentrations of these DFAAs fluctuated greatly. However, the composition (mole \%) of 5-7 DFAAs was stable between the spring and autumn samples within a four-year span. The same concentrations of DFAA as those found in the Teshio River during the time of juvenile imprinting in spring (jASW) and adult homing in autumn (aASW) were prepared after a four-year period. Behavioral experiments addressing upstream selective movement were conducted in a Y-maze. Four-yearold mature male chum salmon captured in the Teshio River showed a significant preference for either jASW or aASW over control water, but they did not display a preference between jASW and aASW, revealing that the longterm stability of the composition of DFAA in the natal stream is crucial for olfactory imprinting and homing in chum salmon (Yamamoto et al. 2013). 
Geomagnetic navigation functions as a mechanism for salmon to reach distant, oceanic foraging grounds and returning to the vicinity of their natal river using the predictable gradients of Earth's magnetic field as a kind of "map" (Putman 2018). Juvenile salmon appear to possess a magnetic map (orientation to spatial information in the magnetic field), but this ability appears to be disrupted if salmon are reared in a strongly variable magnetic field (Putman et al. 2014a). Finally, long-term spatiotemporal variability in the homing routes of salmon can be predicted by assuming specific values of magnetic field parameters imprint upon smolts as they enter seawater and use those values as navigational coordinates upon reaching maturity (Putman et al. 2014b). The use of 'map-like' information from the Earth's magnetic field for orientation has been shown in diverse taxa, but questions remain regarding the function of such maps. A 'magnetic displacement' experiment was carried out to demonstrate that juvenile pink salmon use magnetic cues to orient. The experiment was designed to simultaneously explore whether their magnetic map is used to direct fish (i) homeward, (ii) toward the center of their broad oceanic range, or (iii) along their oceanic migratory route. The headings adopted by these navigationally naive fish coincided remarkably well with the direction of the juveniles' migration inferred from historical tagging and catch data. This suggests that the largescale movements of pink salmon across the North Pacific may be driven largely by their innate use of geomagnetic map cues. Key aspects of the oceanic ecology of pink salmon and other marine migrants might therefore be predicted from magnetic displacement experiments (Putman et al. 2020).
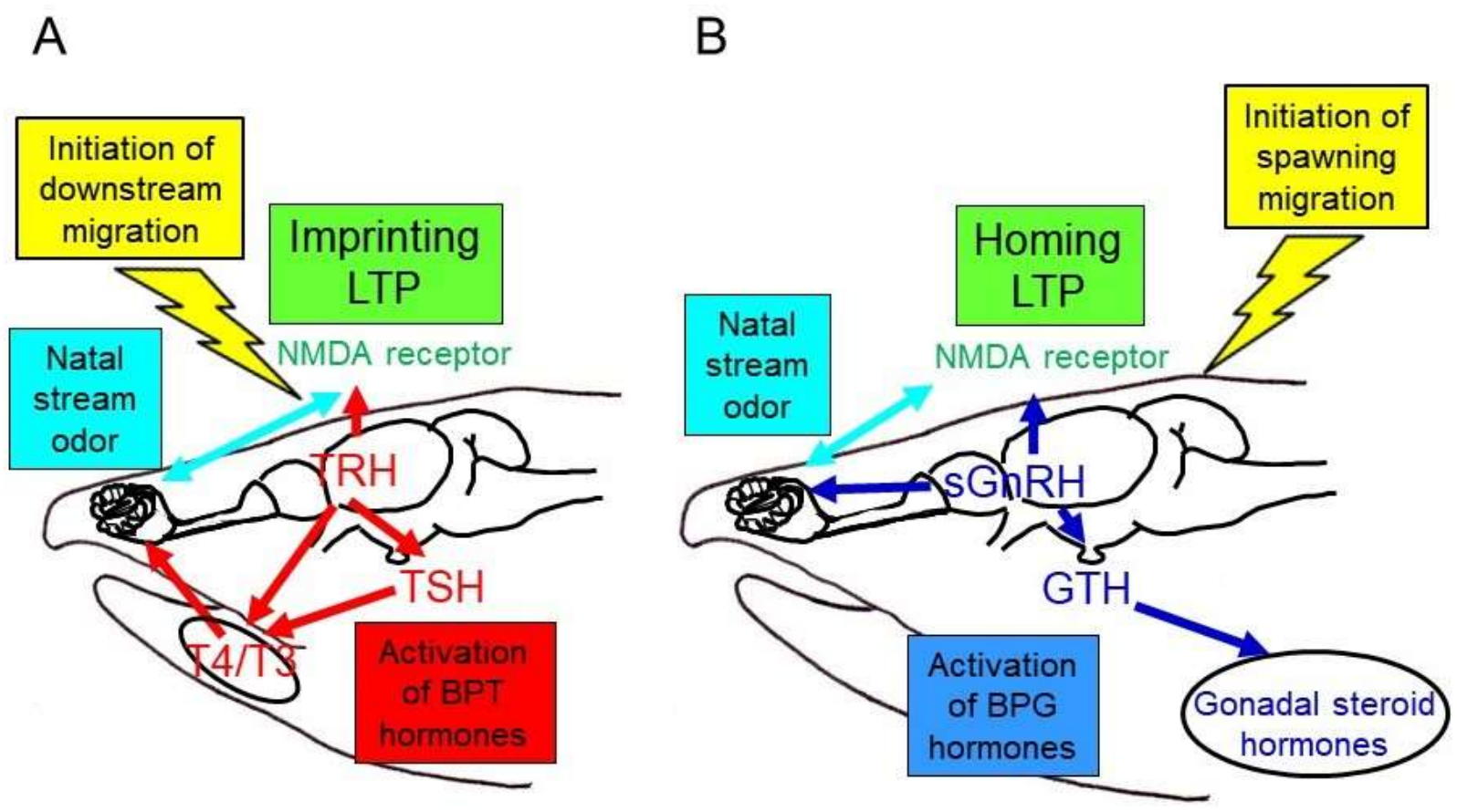

Fig. 2. Schematic illustrations of olfactory imprinting in juvenile salmon (A) and olfactory homing in adult salmon (B). The initiation of the downstream migration of juveniles induces the expression of the brain-pituitary-thyroid (BPT) hormones, which then induce the upregulation of the NMDA receptor, inducing imprinting long-term potentiation (LTP), which enhances olfactory memory formation related to natal stream-specific odors. The initiation of the homing migration of adult salmon induces the activation of the brain-pituitary-gonad (BPG) hormones, which then induce the upregulation of NMDA receptor, inducing homing LTP, which enhances olfactory memory retrieval related to natal stream-specific odors.

The plasticity of the nervous system and synaptic plasticity are fundamental mechanisms for memory formation and retrieval in the brains of vertebrates. The plasticity of the nervous system results from the structural and functional changes of the nervous system that occur in response to stimuli from the outside environment. Synaptic plasticity promotes the ability of chemical synapses to change synaptic strength that is modified to encode memory formation. Long-term potentiation (LTP) is the persistent strengthening of synaptic activity that produces a long-lasting increase in the signal transmission between two neurons that is induced by the $N$-methyl-D-aspartate (NMDA) receptor (Martin et al. 2000). The NMDA receptor plays an important role in memory formation and retrieval and is composed of the essential NR1 subunit and the differentially expressed NR2A-D subunit (Shipton and Paulsen 2013). In hatchery-reared juvenile chum salmon, the environmental changes associated with the release into the river at the initiation of downstream migration induce the activation of the brain-pituitary-thyroid hormones, 
which then stimulate the upregulation of NR1 and induce the induction of LTP, ultimately enhancing olfactory memory formation related to natal river-specific odors. In adult salmon, the salmon gonadotropin-releasing hormone neurons in the preoptic area must be involved in gonadal maturation, and those in the olfactory bulb and terminal nerve may have olfactory-related functions that are related to olfactory-guided homing migration. The initiation of homing migration in adult chum salmon induces the activation of the brain-pituitary-gonad hormones, which then stimulate the upregulation of NR1 and induce the induction of LTP, which subsequently improves olfactory memory retrieval related to natal river-specific odors (Ueda et al. 2016) (Fig. 2). The neural and hormonal mechanisms of geomagnetic imprinting and homing in salmon have not been investigated and should be clarified (Gould 2014).

With the International Year of the Salmon, we believe it fitting to definitively test the olfactory and geomagnetic imprinting and homing hypothesis in Pacific salmon. This can be achieved through careful manipulation of the DFAA and magnetic field during embryonic development and early rearing stages of salmon, thus allowing different groups to be "programmed" to return to specific coastal locations and natal rivers. Differential marking of groups and coordination with fishers allows for a clear test of predictions. Electronic tagging a subset of smolts and stable isotope analyses of returning fish would allow further inferences into the aspects of oceanic ecology influenced by magnetic navigation. This experiment would move salmon research towards process-based models to mechanistically understand and predict spatiotemporal variability in salmon returns (Putman et al. 2019).

\section{REFERENCES}

Gould, J.L. 2014. Animal navigation: a map for all seasons. Curr. Biol. 24(4): R153-R155

Hara, T.J. 1994. The diversity of chemical stimulation in fish olfaction and gustation. Rev. Fish Biol. Fish. 4: 135.

Martin, S.J., P.D. Grimwood, and R.G. Morris. 2000. Synaptic plasticity and memory: an evaluation of the hypothesis. Annu. Rev. Neurosci. 23(1): 649-711.

Putman, N.F. 2018. Marine migrations. Curr. Biol. 28: R952-R1108.

Putman, N.F. 2021. Animal navigation: what is truth? Curr. Biol. 31: R330-R358.

Putman, N.F., A.M. Meinke, and D.L. Noakes. 2014a. Rearing in a distorted magnetic field disrupts the 'map sense' of juvenile steelhead trout. Biol. Lett. 10(6): 20140169.

Putman, N.F., E.S. Jenkins, C.G. Michielsens, and D.L. Noakes. 2014b. Geomagnetic imprinting predicts spatiotemporal variation in homing migration of pink and sockeye salmon. J. R. Soc. Interface 11(99): 20140542.

Putman, N.F., H. Ueda, and D.L. Noakes. 2019. The current status of research on geomagnetic navigation in Pacific salmon. N. Pac. Anadr. Fish Comm. Tech. Rep. 15: 182-186. (Available at https://npafc.org)

Putman, N.F., C.R. Williams, E.P. Gallagher, and A.H. Dittman. 2020. A sense of place: pink salmon use a magnetic map for orientation. J. Exp. Biol. 223: jeb218735.

Shipton, O.A., and O. Paulsen. 2013. GluN2A and GluN2B subunit-containing NMDA receptors in hippocampal plasticity. Philos. Trans. R. Soc. B. Biol. Sci. 369: 20130163.

Shoji, T., H. Ueda, T. Ohgami, T. Sakamoto, Y. Katsuragi, K. Yamauchi, and K. Kurihara. 2000. Amino acids dissolved in stream water as possible homestream odorants for masu salmon. Chem. Senses. 25: 533-540.

Ueda, H. 2019. Sensory mechanisms of natal stream imprinting and homing in Pacific salmon Oncorhynchus spp. J. Fish Biol. 95(1): 292-303.

Ueda, H. 2020. Physiological aspects of imprinting and homing migration in salmon: emerging research and opportunities. IGI Global, Hershey. 160 pp.

Ueda, H., S. Nakamura, T. Nakamura, K. Inada, T. Okubo, N. Furukawa, R. Murakami, S. Tsuchida, Y. Zohar, K. Konno, M. Watanabe. 2016. Involvement of hormones in olfactory imprinting and homing in chum salmon. Sci. Rep. 6: 21102.

Yamamoto, Y., H. Shibata, and H. Ueda. 2013. Olfactory homing of chum salmon to stable compositions of amino acids in natal stream water. Zool. Sci. 30: 607-612. 